\section{US nanotechnology plan lacks risk research}

An independent review has slammed the United States' strategy for research into nanotechnology's potential health and environmental risks.

Generated by the National Research
Council, which provides independent scientific advice for the US government, the 10 December report criticizes the federal plan for not having specific goals, central accountability or sufficient input from interested parties. It also says that unrelated research, such as projects on the delivery of medicines using nano-sized tools, is passed off as research on health risks. That work is

\title{
Rift-valley countries set for geothermal power
}

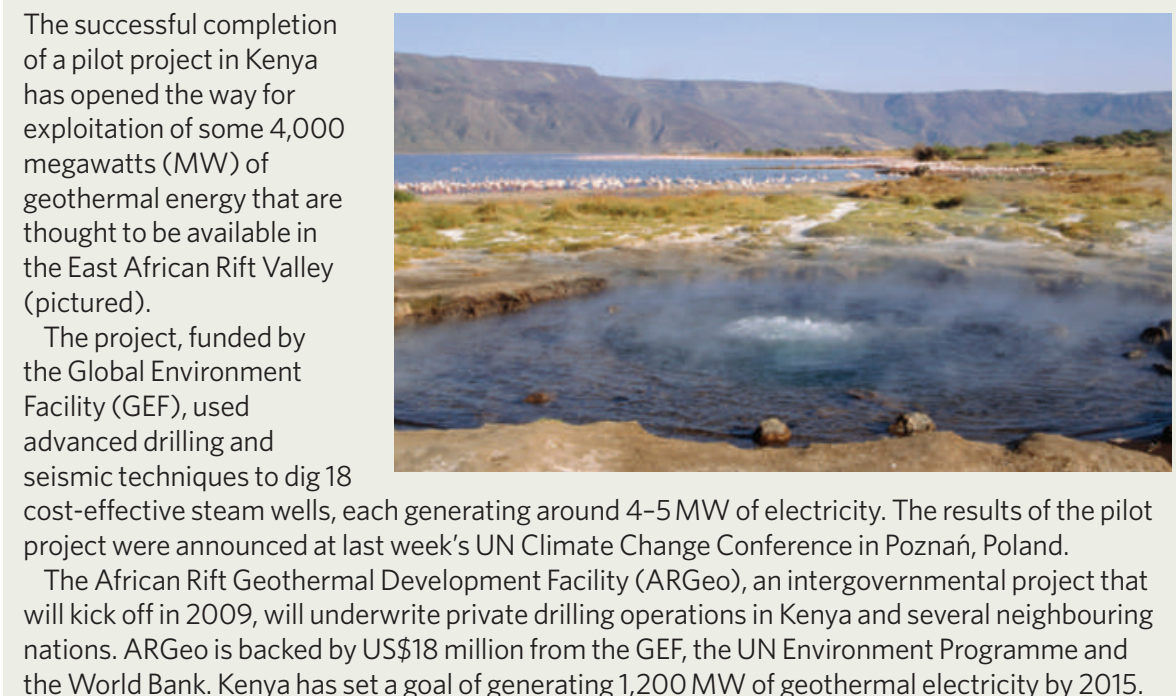

The successful completion

of a pilot project in Kenya

has opened the way for

exploitation of some 4,000

megawatts (MW) of

geothermal energy that are

thought to be available in

the East African Rift Valley

(pictured).

The project, funded by the Global Environment

Facility (GEF), used

advanced drilling and

mic techniques to dig 18

project were announced at last week's UN Climate Change Conference in Poznań, Poland.

will kick off in 2009, will underwrite private drilling operations in Kenya and several neighbouring

the World Bank. Kenya has set a goal of generating 1,200 MW of geothermal electricity by 2015.

"really tangential", says report chair David

Eaton, a professor of environmental health at the University of Washington in Seattle.

Changes to the government's plan that would have addressed some of these concerns were nearly legislated by Congress this year, but the effort quietly expired in the Senate.

\section{Lectures gain electronic life in Egyptian library}

Scientists from around the world are donating their lectures to the Bibliotheca Alexandrina in Alexandria, Egypt. These 'golden PowerPoint' presentations will be available from January for any academic to download and use.

The resource is aimed primarily at teachers and scholars in developing countries - as long as they have Internet access. The goal is to gather 100,000 lectures on medicine, engineering, environmental sciences and agriculture within the first year.

The Bibliotheca Alexandrina was opened six years ago, nearly two millennia after the original library, which housed all the knowledge of the Ancient Greeks and Persians, was destroyed. The new project aims to evoke its mission in the digital age. www.bibalex.org/supercourse 